\title{
Erratum: New local field quantity describing the high gradient limit of accelerating structures [Phys. Rev. ST Accel. Beams 12, 102001 (2009)]
}

A. Grudiev, S. Calatroni, and W. Wuensch

(Received 31 August 2011; published 20 September 2011)

DOI: $10.1103 /$ PhysRevSTAB.14.099902

PACS numbers: 52.80.Vp, 29.20.Ej, 99.10.Cd

We have identified an omission in our paper. The absolute value of the real part $\|\Re\{\bar{S}\}\|$ and the absolute value of the imaginary part $\|\widetilde{S}\{\bar{S}\}\|$ of the complex Poynting vector $\bar{S}$ have to be used in Eq. (16). Thus, the correct expression for the modified Poynting vector is

$$
S_{c}=\|\Re\{\bar{S}\}\|+g_{c} \cdot\|\Im\{\bar{S}\}\| .
$$

The results and conclusions of the article are not effected.

Published by the American Physical Society under the terms of the Creative Commons Attribution 3.0 License. Further distribution of this work must maintain attribution to the author(s) and the published article's title, journal citation, and DOI. 